\title{
OBSERVACIONES CLINICAS sobre la gangrena gaseosa del útero
}

\author{
Dr. Saulo Muñoz Delgado \\ Dr. Reinaldo Mora Restrepo \\ Dr. Jorge Escobar Soto
}

De la Clínica de Maternidad de Cali

Ha sido dolorosa nuestra experiencia al ver morir pacientes jóvenes en forma más o menos inesperada, cuando creíamos que los tratamientos que estábamos usando darían buenos resultados. Así en el año de 1955 murió una de nuestras pacientes toxémicas, y a comienzus de 1958 otra murió sin que esperáramos resultados fatales. La autopsia de estas pacientes reveló la presencia de infecciones causadas por Clostridium Welchii.

La revisión cuidadosa cie estos casos y de la literatura sobre la infección causada por bacilo de Welchii en pacientes obstétricas nos llevo a establecer el estudio bacteriológico completo de las pacientes que presentaron sintomas definidos de sepsis o en quienes se sospechara la posibilidad de infección durante su permanencia en el Hospital.

Un mejor estudio de nuestros casos nos hizo pronto comprobar un cuadro clínico que nos ha permitido hacer el diagnóstico precoz de infección debida a Clostridium Welchii.

Presentamos nuestras observaciones porque estamos seguros de que el diagnóstico precoz es posible ya que el cuadro clínico permite diferenciarlo de sepsis causada por otros gérmenes. La pronta aparición de la ictericia y su rápido progreso, así como los signos iniciales de falla renal hacen que la sintomatología sea diferente a otros casos serios de infecciones como las causadas por Estreptococo hemolítico. 
Hacemos énfasis sobre la necesidad del diagnóstico clínico precoz, ya que la comprobación bacteriológica, por las dificultades técnicas que encierra, en general demora más de 48 horas. Este tiempo es precioso para establecer un tratamiento adecuado, pues es hoy aceptado que el pronóstico es un poco menos grave si el avance de las lesiones no llega a puntos en que se hace imposible su curación.

La paciente que se va recobrando del problema de infección, ofrece la dificultad del manejo adecuado de su lesión tubular. Esta requiere instituír métodos de control y tratamiento desde el comienzo de la enfermedad siendo una lesión tanto más severa cuanto más tiempo se deje transcurrir en la evolución de la enfermedad. La eliminación de los productos nitrogenados y el balance de sodio y potasio en especial. deben ser cuidadosamente ilevados hasta la regeneración de los túbulos. Es en esta etapa de la enfermedad cuando suceden los grandes fracasos.

En este trabajo presentamos también observaciones sobre el llamado tratamiento "agresivo" del aborto séptico incompleto, como método de suprimir el foco infeccioso de nuestras pacientes. Este procedimiento lo hemos seguido durante el último año en pacientes que presentan infecciones post-abortum, sin tener en cuenta el germen patógeno responsable. Los resultados que estamos obteniendo serán motivo de publicación posterior.

\section{MATERIAL}

Desde junio de 1955 hasta finales de 1958 hemos tenido cinco casos de infecciones severas por Clostridium Welchii. De estas pacientes 4 nan sido tratadas en la Clínica de Maternidad de Cali y la otra nor falta de suero antigangrenoso enviada para su tratamiento al Departamento de Medicina Interna (Dr. Jorge Araújo), del Hospital Departamental Universitario. Las dos primeros pacientes murieron sin diagnóstico, con fetos in útero y la autopsia (A) reveló gangrena uterina. Una vez establecidas las bases clínicas para el diagnóstico, pudimos hacerlo en los 3 últimos casos tan pronto ingresaron a la Clínica, pero su estado era tan severo nue una murió a las pocas horas y la otra después de

(A) Los exámenes post-mortem se hicieron en el Departamento de Patología de la Facultad de Medicina, de la Universidad del Valle. 
16 días de tratamiento. El caso que sobrevivió fue tratado en el Hospital Departamental Universitario.

En los 3 últimos casos hemos practicado exámenes comprobatorios como frotis del cuello, cultivos de cavidad uterina, y hemocultivos (B). Con un aplicador se obtienen muestras de la vagina, el cuello y la cavidad uterina. Para evitar contaminaciones en el cultivo de la cavidad uterina pasamos el aplicador a través de un tubo ccnductor de vidrio que se ha introducido hasta el cue1lo. Una vez tomado el cultivo regresamos el aplicador a la parte

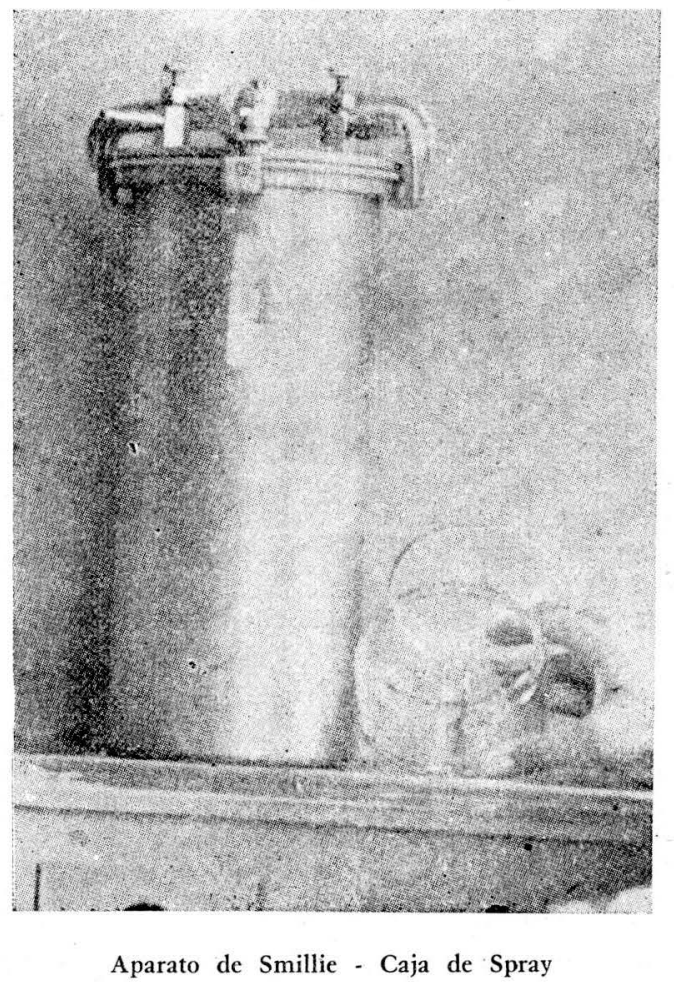

media del tubo de vidrio y retiramos el tubo con el aplicador dentro. Los aplicadores se siembran en BHI (Brain Heart Infusion) y en medio de tioglicolato los cuales son medios de enriquecimiento de gérmenes aerobios y anaerobios respectivamente. En el labo-

(B) Los exámenes bacteriológicos fueron practicados en el laboratorio del Departamento de Medicina Preventiva bajo la dirección del Dr. Miguel Gracián. 
ratorio se hacen los frotis directos y tinción con el método de Gram y de acuerdo con los resultados obtenidos se siguen los siguientes caminos: A) cocos Gram positivos, se siembran en cajas de agar sangre y aerobiosis y atmósfera de CO2. Se hace lectura de los cultivos a las 24 horas. B) Bucilos Gram positivos, se siembran en cajas de agar sangre en aerobiosis y anaerobiosis, la lectura se realiza a las 24 ó 48 horas. Si la morfología es compatible con anaerobios patógenos, se hace prueba diferencial de azúcares y practicamos lectura a las 24 y 48 horas. Para la siembra de los bacilos Gram positivos en agar sangre y en medio anaerobio empleamos las cajas de Spray la cual tiene dos pequeñas cámaras en una de las cuales se ponen $4 \mathrm{cms}$. de ácido pirogálico al $40 \%$ y en la otra $10 \mathrm{cms}$. de hidróxido de sodio al $20 \%$. Sellamos las cajas con plastilina y mezclamos estos líquidos verificando así procesos de oxidación que dejan el medio anaerobio. Ultimamente estamos practicando cultivos para anaerobios en el aparato de Smillie que al ser cerrada la campana e introducir gas propano deja el medio en completa anaerobiosis. El gas propano se cambia dos veces y la tercera se deja llenar el aparato completamente. Las lecturas se verifican a las 24 y 48 horas.

Simultáneamente con las muestras de cavidad uterina y los frotis de vagina y cuello tomamos sangre para hemocultivo el cual lo repetimos en caso de que la infección persista.

\section{CASOS CLINICOS}

\section{CASO No 1}

H. Cl. No $\quad$ Clínica de Maternidad de Cali.

Fecha de ingreso: junio 22/55.

Fecha de ruerte: julio $6 / 55$.

Causa de Ingreso: Grávida II para I, que ingresó por dolor hipogástrico con embarazo de más o menos 30 semanas. Preeclampsia severa. Feto muerto.

Examen físico: Paciente en malas condiciones generales, con facies angustiosas. TA: 180/90, Pulso 90, Temperatura $36,8^{\circ} \mathrm{C}$. Altura uterina: $22 \mathrm{cms}$. Feto en presentación cefálica, alta. Ruidos cardíacos negativos; no hay contracciones uterinas.

Se hospitalıza con el diagnóstico de preeclampsia severa. Quince minutos después presenta convulsiones ténico-clónicas después de un estado de excitación. Se presentan dos nuevos estados convulsivos con intervalos de 1/2 hora. 
Evolución: El día 23 está estupurosa con pulso y temperatura dentro de límites normales; la Tensión Arterial es de 180/90. Presenta hematuria y epistaxis intensas, por lo cual se practica taponamiento nasal y se prescriben coagulantes. Se hace inducción del parto con 5 unidades de Pitocín en solución dextrosada, no obteniéndose respuesta, por lo cual se repite nuevamente 8 horas más tarde con igual resultado. En los días 24, 25. 26 y 27 la Tensión Arterial se sostuvo alrededor de 100/70, con aceptable eliminación urinaria. El día 27 presenta hipertermia de $28^{\circ} \mathrm{C}$., con Tensión Arterial menor de $100 / 70$, y marcada oliguria.

Los días 28, 29 y 30 la Tensión Arterial oscila alrededor de 90/70 y prezenta dolor epigástrico continuo. Las deposiciones son fétidas, de color oscuro.

Los días 1, 2 y 3 se administró terramicina I. M. a pesar de estar afebril. El día 4 se hace amniotomía. El día 5 se inician contracciones cada 10 minutos por espacio de 2 horas; se suspenden las contracciones y se inicia administración de 5 unidades de Pitocín intramuscular cada $1 / 2$ hora, sin resultado alguno. Al tinalizar el día 5 las contracciones son nulas.

A las 7 p. m. del día 6 de julio murió en forma silenciosa.

\section{CASO $\mathbf{N}^{0} 2$}

H. Cì. No 201-1-59.

Edad: 27 ańos.

Fecha de ingreso: enero 11/58 (h.: 18:30).

Fecha de inuerte: enero 13/58 (h.: 21:00).

Causa de ingreso: Grávida 1 para 0 . Embarazo de 40 semanas. Trabajo de Parto. Paciente clasificada como oligofrénica que no colabora al interrogatorio.

Examen físico: Tensión Arterial: 130/70, Pulso 100, Temperatura 39².

Cuello dilatado $5 \mathrm{cms}$. y borrado $80 \%$ en O.D.P., estación 0.

Membranas íntegras. Se inicia Penicilina-Estreptomicina (400.000 unidades $\mathrm{x} \quad 1 / 2$ gramo).

Enero 12 a las 23 horas el mismo dato del ingreso.

Enero 13 a las 9:35 -90\%- $5 \mathrm{cms}$. Membranas rotas. Flujo vaginal oscuro y fétido.

Ruidos fetales negativos. Utero hipertónico.

Enero 13 a las 15:30 -90\%- O.D.P. en 0. Utero hipertónico.

Enero 13 a las 21. Muere en forma casi repentina. Se envía a Patología. 


\section{CASO No 3}

H. Cl. No 119-5-58. Clínica de Maternidad de Cali.

Fecha de ingreso: mayo 7/58 (h.: 13:00).

Fecha de muerte: mayo $8 / 58$ (h.: 2).

Causa de ingreso: Grávida 1 rara 0, que ingresó con el diagnóstico de aborto incompleto séptico de más o menos 14 semanas. Manifestó la paciente que 4 días antes sufrió un traumatismo (caída) que inició dolor hipogástrico continuo sin irradiación y 4 horas antes de su ingreso abortó.

Examen físico: Paciente en malas condiciones generales, letárgica, con Tensión Arterial de 70/50, Pulso $128 / \mathrm{m}$. y Temperatura de $37^{\circ} \mathrm{C}$.

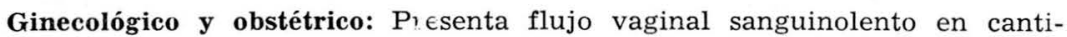
dad moderada. T. V.: Cuello borrado $60 \%$ dilatado $11 / 2 \mathrm{cms}$. Utero aumentado para más o menos 14 semanas (10 cms. por encima del pubis), doloroso. Anexos y fon rio de saco libres. Mamas secretantes.

Evolución: A las 15 horas, paciente estrupurosa. Utero en contracción permanente, doloroso aumentado más o menos a $14 \mathrm{cms}$. por encima del pubis.

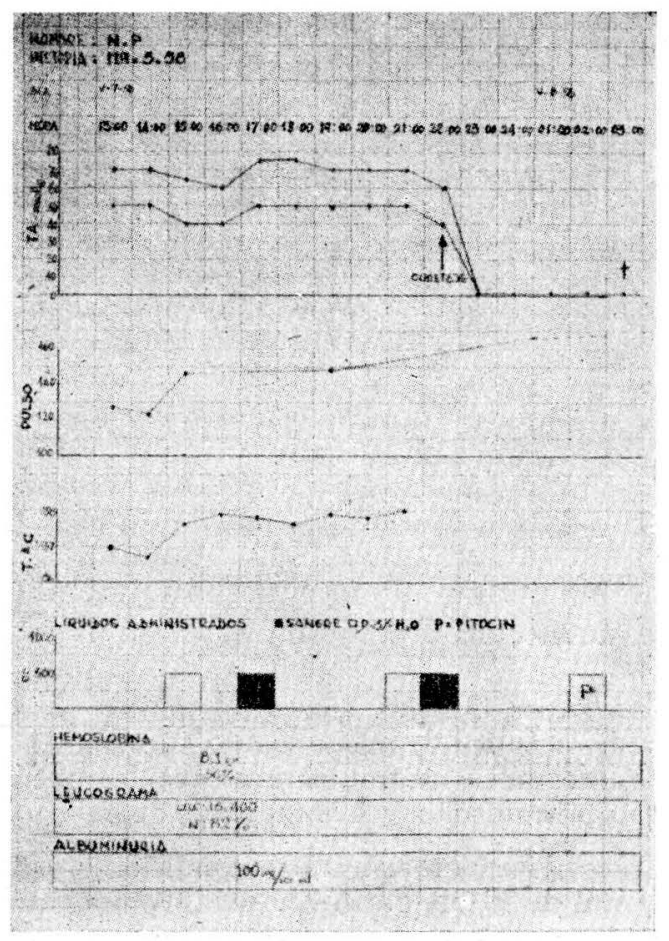


Sonda vesical. Se nota crepitación sobre el útero. Secreción fétida. Hay defensa abdominal.

Impresión: Aborto incompleto séptico por Clostridium Welchii.

Se ordena tratamiento consistente en: Penicilina 400.000 unidades cada 6 horas. Tetraciclina $100 \mathrm{mgr}$. I.M. cada 6 horas y suero antigangrenoso 500.000 unidades cada 12 horas (no se consiguió).

A las 22 horas se hizo revisión de cavidad por la sospecha de perforación uterina con Clostridium Welchii sobreagregado y se extrajeron abundantes restos ovulares de olor fétido.

Histerometría: $14 \mathrm{cms}$. Se tomaron muestras para frotis y cultivos.

Mayo 8, hora 2:00: Paciente en malas condiciones. Sudorosa y pálida. Conjuntivas ictéricas. Respiración irregular. Se practica sondeo vesical obteniéndose orina oscura, en poca cantidad. Se ordena Cortisona $10 \mathrm{mgr}$. y sangre total. Para evolución del caso consultar la gráfica adjunta.

\section{CASO $\mathbf{N}^{0} 4$}

H. Cl.: 9-3-59. Clínica de Maternidad de Cali.

Fecha de ingreso: marzo 2/59 (h.: 17:00).

Fecha de muerte: marzo 18/59 (h.: 20:40).

Causa de ingreso: Grávida 4 para 2, con aborto inevitable de más o menos 12 semanas. Desde hace 15 días presenta anorexia, astenia, náuseas y vómito alimenticio. Diarrea hasta con 15 deposiciones al día. Desde ayer inició ictericia y marcada oliguria. Hemorragia vaginal moderada, acompañada de dolor hipogástrico.

Examen físico: Paciente en muy mal estado nutricional que parece agudamente enferma. Conjuntivas ictéricas.

T. A.: $110 / 50$, Pulso 90 , Temperatura $37,8^{\circ} \mathrm{C}$.

Ginecológico: Hemorragia vaginal escasa de olor fétido. Cuello borrado y dilatado de 2 a $3 \mathrm{cms}$. Fondo de saco libres pero dolorosos. Utero en posición normal, consistencia blanda y aumentado de tamaño como para un embarazo de más o menos 12 semanas. Se logran palpar restos ovulares.

Impresiỏn: Aborto incompleto séptico. Infección por Clostridium Welchii? Hepatitis viral?

Exámenes de laboratorio: Galli negativo. Bilirrubina: total $4 \mathrm{mgr}$. Leucocitos 39.000. Hemoglobina 7 grs. Urea $211 \mathrm{mgr}$. Albuminuria $100 \mathrm{mgr}$ \%. Coprológico quistes de histolítica: Timol: 4.24 unidades. 
Tratamiento y evolución: Continúa con deposiciones diarreicas y al día siguiente se hizo legrado instrumental. Se comenzó tratamiento con Penicilina Cristalina 500.000 unidades, cada 4 horas, vitamina $\mathrm{K}$, y dieta con restricción líquida. Dos días después presentó ligera contractura en músculos abdominales, reflejos exaltados y herpes bucal. Cultivo: Clostridium Welchii. La ictericia y la retención nitrogenada aumentaron progresivamente a pesar de encontrar inejoría clínica. La oliguria se mantenía. Dos días después pre-

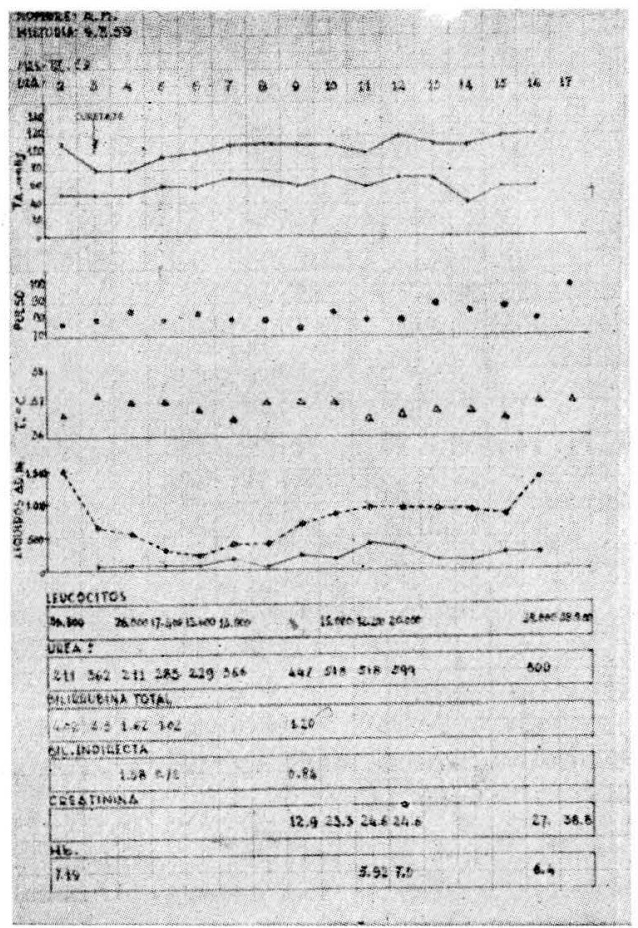

sentó vómito amarillo, negrusco, orina piúrica, por lo cual se hicieron irrigaciones vesicaies. El vómito obligó a suspender la dieta oral administrándose glucosa al $10 \%$ con aumento de la eliminación urinaria pero sin variación de la retención nitrogenada. Dos días más tarde presentó desorientación y convulsiones focales en cara y más tarde obnubilación y presencia de abundantes secreciones bronquiales. Se administra oxígeno y se hace aspiración de secreciones. El día 16 de marzo presentó reflejos exaltados, y convulsiones en traba: Urea $800 \mathrm{mgr} . \%$, Potasio $5,7 \mathrm{mEq} /$ Litro, Sodio $12 \mathrm{mEq} /$ Litro, Creatinina $87 \mathrm{mgr} . \%$, Nitrógeno Uréico $374 \mathrm{mgr} \%$, eliminación urinaria en 24 horas 320 c.c. La paciente continúa en coma con reflejos exaltados y convulsiones focales hasta el momento de su muerte a las 8:40 horas del 18 de marzo, precedida por gran cantidad de estertores bronquiales, taquicardia y velamiento de los ruidos cardíacos. 


\section{CASO No 5}

H. Cl.: 34-271. Hospital Departamental Universitario.

Fecha de ingreso: julio 18/58.

Fecha de salida: octubre $2 / 58$.

Causa de ingreso: Aborto incompleto séptico e ictericia.

Grávida 1 para 0 con amenorrea desde mayo 5/58. Desde ayer presenta hemorragia vaginal con coágulos y acompañada de fuerte dolor hipogástrico, fiebre y escalofrío, náusea, vómito y orina color muy oscuro. Visión borrosa y obnubilación marcada.

Examen físico: Paciente de unos 25 años mal nutrida, que da la impresión de estar agudamente enferma. Conjuntivas ictéricas. Dolor marcado en el hipocondrio derecho y epigastrio.

Tensión Arterial 90/60, Pulsc 88, Temperatura 36,4ำ.

Ginecológico: Utero aumentado de tamaño para 8 semanas de embarazo con cuello entreabierto y se palpan restos ovulares. Dolor a la movilización del útero y palpación de los anexos

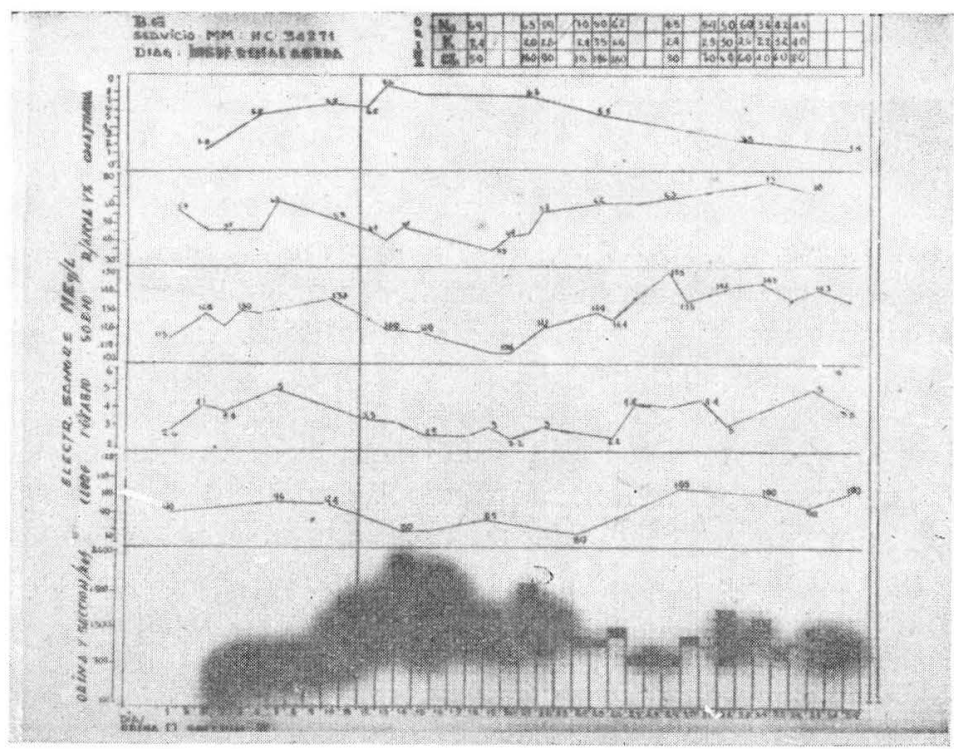

Evolución: Se extraen con pinzas restos y se practica curetaje para extraer la mayor cantidad de ellos. Se toman muestras para cultivos y frotis. 
Presenta ariuria y se instituye tratamiento para insuficiencia renal aguda. Náusea, vómito y diarrea. Se reemplazan líquidos y electrolitos. Se consideraron como requerimiento básico 600 c.c. y el resto se reemplazó con Dextrosa al $5 \%$ en Solución Salina y agua bicarbonatada al $1 \%$.

Los cultivos se reportaron como Clostridium Welchii. Se administró suero antigangrenoso en dosis de 50.000 unidades. Hacia la mitad de la fase anúrica presentó píaquetopenia por lo cual se le administraron $20 \mathrm{mgr}$. de Prednisolona por 10 veces. Se ordenaron posteriormente antibióticos de amplio espectro y sueio antigangrenoso 20.000 unidades cada 6 horas.

\section{OBSERVACIONES CLINICAS}

El Clostridium Welchii se encuentra en una forma saprofita en la vagina sin que se presente ningún síntoma de infección. Solamente en algunos casos el germen se vuelve patógeno lo que indica que se requieren condiciones especiales para su desarrollo. Siendo un germen anaerobio y presentándose con mayor frecuencia en los casos de aborto incompleto séptico, es lógico pensar que los tejidos necróticos sean el medio más propicio para su proliferación. La localización es uno de los factores que determinan el cuadro clínico y la razón por la cual los síntomas se presentan desde leves hasta las infecciones más severas. Por lo tanto haremos primeramente una descripción de las diversas localizaciones de la infección y luego nos referiremos a sus formas clínicas.

LOCALiZACION (4). 1 - VAGINA. - En los frotis vaginales practicados a pacientes ya sean ginecológicas u obstétricas, hemos encontrado la presencia de Clostridium Welchii 4 veces sobre 56 casos, sin producir signo clínico alguno de infección. Las estadísticas de otros autores (1) fluctúan desde el $4,5 \%$ hasta el $5,9 \%$.

2 - INFECCION UTERINA. - La localización en el útero se caracteriza por dolor, aumento de tamaño y en ocasiones presencia de fisiometra y sensación de crepitación. Algunos autores (16) creen que la crepitación solamente se presenta en la fase final o es un hallazgo post-mortem. En el caso $\mathrm{N}^{\circ} 3$ Hist. $\mathrm{N}^{0}$ 119-5-58, fue posible encontrarla claramente al ingreso de la paciente 6 horas antes de su muerte.

3 - DISEMINACION A LA PELVIS Y PERITONEO. $\mathrm{Su}$ extensión se hace invadiendo el parametrio y es una condición bastante severa. 
4 - VIA SANGUINEA. - Debemos considerar 3 formas diversas de extensión de la infección:

a) Bacteremia: los hemocultivos son positivos sin presentar otros signos de septicemia diferentes a la fiebre.

1

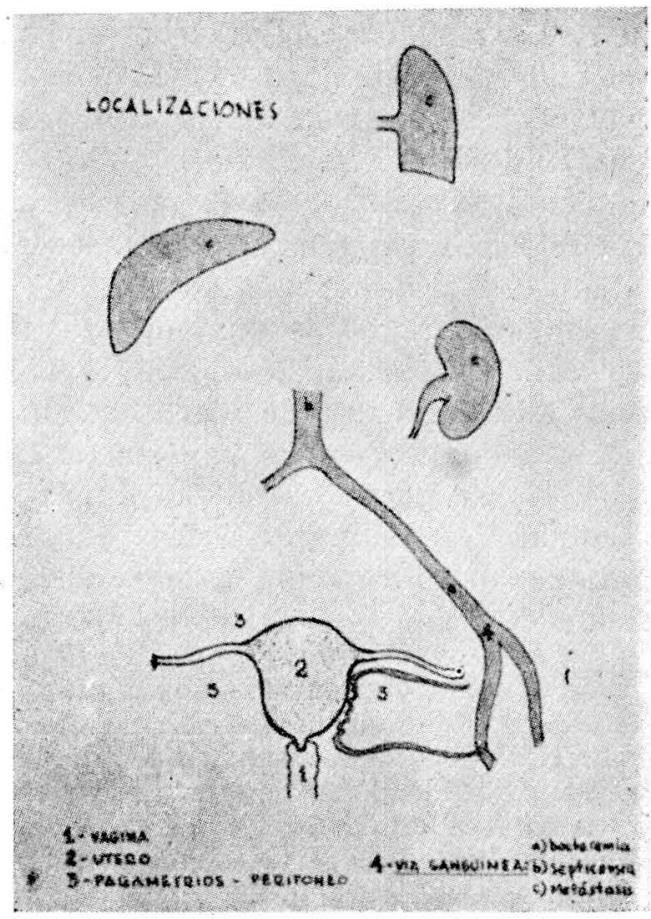

b) Septicemia: evolución en una forma fulminante y en algunos casos no es posible identificar el Clostridium Welchii en los hemocultivos $\mathrm{u}$ obtener gérmenes en los medios de crecimiento porque no sobrevive por largos períodos en la sangre ya que es un anaerobio estricto.

c) Metástasis: Se puede extender a otras partes del cuerpo con o sin signos de septicemia. En los reportes patológicos y en nuestros casos las hemos encontrado con más frecuencia en el hígado y el riñón y en dos de los casos se encontraron metástasis en todos los órganos. 


\section{CUADRO CLINICO}

Para una comprensión del cuadro clínico lo dividimos en los siguientes períodos:

a) Iniciación, b) Fase ictero-hemolítica, c) Fase renal y d) Fase final o muerte.

a) Iniciación: La mayoría de las veces el cuadro es consecutivo a manipulaciones practicadas ya sea por abortos o sobre la cavidad uterina, con un período de incubación de 24 a 48 horas después de las cuales se inicia escalofrío, fiebre, náuseas y vómito y ocasionalmente diarrea (11). El pulso presenta una desproporción en relación con la temperatura encontrándose elevaciones de 120 a 140 con alzas térmicas de $37,5^{\circ} \mathrm{C}$. o casi normal. Por lo tanto la temperatura no es un índice de la severidad de la enfermedad o de la respuesta de la terapia (11). El pulso y la tensión arterial dan mejor criterio pronóstico. La T.A. tanto la sistólica como la diastólica, en la mayoría de los casos es baja. Al examen pélvico se puede encontrar un flujo oscuro, fétido y dolor abdominal. Los hallazgos físicos pueden ser pocos al comienzo presentando deshidratación y moderado o severo dolor muscular así como ictericia.

b) Fase ictero-hemolítica: Esta fase o síndrome según Mahn y Dantuono dura aproximadamente de 5 a 8 días y se caracteriza por ictericia o una coloración cobriza debida a hemólisis y cianosis con colapso vascular. Esto se debe a la toxina hemolítica que produce el $\mathrm{Cl}$. Welchii la cual destruye los glóbulos rojos en promedio de 300.000 a 600.000 diariamente con disminuciones en los promedios de hemoglobina (2). Esta anemia es de tipo hemolítico (11). El suero sanguíneo presenta un color rojo brillante debido a la presencia de hemoglobina. Las plaquetas disminuyen en un 50\%. Varios grados de trombocitopenia se pueden presentsr (11). En algunas ocasiones se encuentran hemorragias, ya sean hematemesis, melena o epistaxis. Esta última fue en capilares. Estudios espectroscópicos hechos por Ishman y Finch (11) demostraron que el responsable de la coloración del plasma era el radical hem. Hill (15) informó que los pigmentos se debían a hemoglobina libre y metahemoglobina.

El recuento leucocitario generalmente está elevado con una desviación hacia la izquierda en la serie granulocítica (11). 
La icterjcia y anemia progresivas en un paciente que parece más seriemente enfermo que lo que demuestra el estado febril, es para Douglas (4) un signo que llama la atención en el diagnóstico de estas infecciones.

La hemólisis produce orinas de color café y el hallazgo de albúmina casi constante (3). Hay un aumento en la urobilina pero no fue posible identificar sales biliares o pigmentos. El sedimento urinario puede presentar glóbulos rojos pero han sido escasamente observados (2).

Las cifras de bilirrubina pueden fluctuar de 25 a 50 mlgs. \% y se encuentra disminución en el calcio sérico, en las proteínas y en las determinaciones de cloruros (2).

La esferositosis y el aumento de la fragilidad osmótica son hechos sobresalientes en estos casos (1-8) y deben por lo tanto hacerse recuentos globulares de rutina ya que pueden llegar en esta forma al diagnóstico en las infecciones por Clostridium Welchii. (8).

Se presentan mialgias generalizadas, artralgias, y otros signos de hipersensibilidad. Estos efectos se deben a la miotoxina y a la neurotoxina (2).

Fase renal: Si la paciente ha sobrevivido se presenta la oliguria y se iricia el cuadro de insuficiencia renal aguda. Esta lesión renal resulta de diversas condiciones en las cuales hay una repentina hemólisis intravascular, isquemia renal o la introducción de substancias tóxicas. Los estudios experimentales de Trueta (4), han sido capaces de producir lesiones similares en los animales poc la inyección de toxina de estafilococo. En los casos presentados por Hill se informa sobre un gran número de pacientes con insuficiencia renal aguda asociada a Clostridium Welchii. El mecanismo por el cual se produce no está perfectamente claro (4) pero parece que sea la misma causa de otras condiciones capaces de producir hemólisis masiva intravascular. Bajo condiciones de acidez en la orina y probablemente en la presencia de epiteiio tubular lesicnado, la hemoglobinuria produce depósitos de cristales de hem en el túbulo colector distante (4). La lesión del epitelio tubular puede ser debida a isquemia o a substancias tóxicas que se originan en la placenta o a elementos de las células sanguíneas hemolizadas (4). 
Fase final: Las causas más frecuentes de muerte fueron en la mayoría de los casos debidas a la septicemia que conduce por lesión cardíaca al desfallecimiento. También es frecuente el colapso vascular por el cuadro infeccioso. En otros casos el edema pulmonar agudo fue la causa final de la muerte y en nuestra serie la mayoría se debió principalmente a esta última.

En los tres primeros casos descritos la causa de la muerte precisamente se debió a edema agudo pulmonar por haberla sobrehidratado durante la fase de colapso vascular y anuria.

La muerte puede sobrevenir en algunos casos rápidamente o presentarse después de varios días y más que todo como una complicación debida a las toxinas elaboradas, las cuales lesionan los órganos vitales en especial el hígado, riñones y vasos sanguíneos (2). Eistas toxinas han sido descritas como hemolítica, necrotizante, neuro-toxina y miotoxina. La hemolítica produce ictericia, y hemoglobinuria. La necrotizante lesiona los vasos sanguíneos y el epitelio renal. La lesión sobre los vasos produce fenómenos hemorrágicos como melenas, hematemesis, epistaxis etc. La neuro-toxina conduce a la muerte en 24 horas porque afecta los centros nerviosos vitales. La miotoxina produce dolores musculares, calambres e hipersensibilidad (2).

La mortalidad varía desde el $73.3 \%$ (2) hasta el $63 \%$ (4) de acuerdo con el diagnóstico y el tratamiento precoz. En nuestra serie los 2 primeros casos murieron sin que se les hubiera hecho un diagnóstico. En cambio en el último año, cuando ya se está haciendo caso a este tipo de infecciones y se han logrado diagnósticos inmediatos a la admisión, la mortalidad ha reducido.

\section{PATOLOGIA}

La lesión patológica se caracteriza por focos de gangrena y presencia de émbolos sépticos diseminados en los diferentes órganos y cuyo punto de partida ha sido el útero.

Las metástasis que hemos encontrado en orden de frecuencia son: 1) riñón, 2) bazo, 3) hígado, 4) corazón y diversos órganos más.

Describuremos brevemente las diferentes lesiones tanto macroscópicas como microscópicas. 
Cavidad abdominal. Gas maloliente, exudado serofibrinoso.

Utero. Globuloso con paredes blandas y crepitación, congestión y equimosis. En un caso, gas sub-peritoneal proveniente del útero. A los cortes se encontraron paredes de aspecto necrótico y la cavidad llena de gas maloliente.

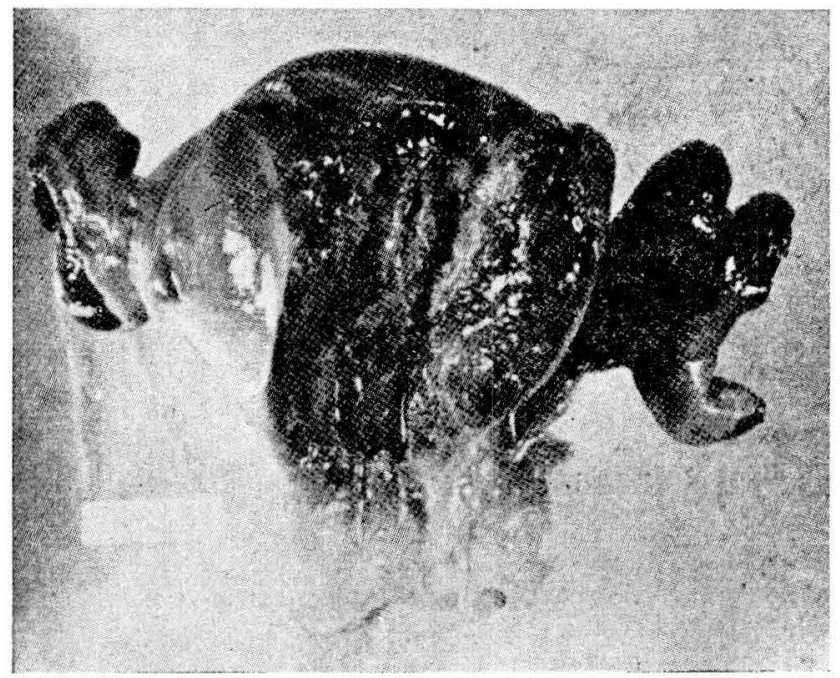

Microscópico: Necrosis por coagulación y abundante presencia de bacilos. Vasos trombosados y zonas hemorrágicas.

Riñón. Consistencia blanda y edema de la porción cortical. Abscesos por vesículas gaseosas.

Microscópico: Presencia de gran cantidad de bacilos y cambios similares a los de una pielonefritis.

Bazo. Consistencia blanda y friable.

Microscúpico: Trombosis con abundantes bacilos.

Higado. Consistencia blanda con numerosos abscesos gaseosos. Gas subcapsular que le da aspecto moteado. Presencia de abscesos y marcada friabilidad. 
Microscópico: Abundantes bacilos. Dilatación de las sinuosidades por congestión y ligera infiltración de mononucleares en los espacios porta en uno de los casos.

Pulmones. Presencia de gas en la cavidad pleural y olor fétido. Edema y presencia de líquido espumoso y sanguinolento en vías aéreas superiores.

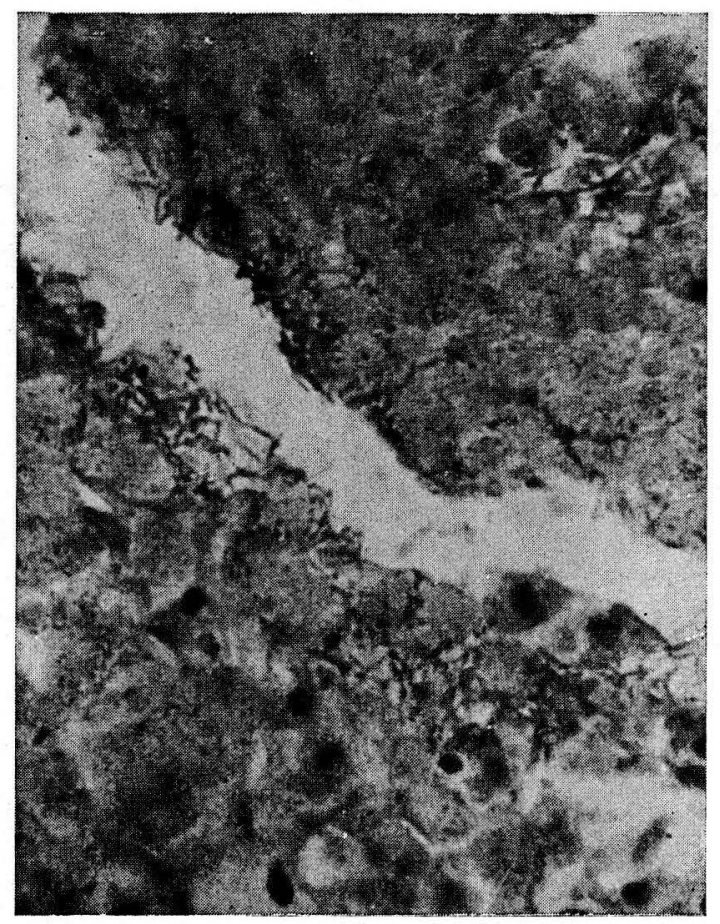

Presencia de Bacilos en un espacio vascular

Microscópico: Trombosis vasculares y presencia de gran cantidad de bacilos. En 2, encontramos un caso compatible con edema agudo pulmonar y en la otra una bronconeumonía por Clostridium Welchii.

Además se encontraron trombosis sépticas diseminadas en varios de los demás órganos sobre todo en cerebro, páncreas, suprarrenales y en la placenta. 


\section{TRATAMIENTO}

Los principios básicos en el tratamiento de este tipo de infecciones, los podemos resumir en los siguientes puntos:

a) Suprimir rápidamente el foco infeccioso.

b) Neutralizar las toxinas circulantes.

c) Aplicación de antibióticos.

d) Medidas de mantenimiento.

\section{A - EXTIRPACION DEI FOCO DE LA INFECCION:}

La evacuación del útero mediante dilatación y curetaje es una de las medidas recomendadas por los diversos autores (2-3). Conociendo que el Clostridium Welchii es un germen que se encuentra en un gran porcentaje en la vagina $8,7 \%$ (4) y que solamente cuando está asociado a traumas o tejido necrótico llega a ser patógeno, se explica la razón por la cual se aconseja practicar legrado con el fin de evacuar estos tejidos. De esta manera el curetaje viene a ser una medida al mismo tiempo preventiva y curativa ya que extirpa los posibles medios de proliferación.

En la serie de Mahn y Dantuono (2) el curetaje se practicó en 67 de los 75 casos de los cuales en $47,7 \%$ se hizo en las primeras 24 horas y en $52,3 \%$ en las primeras 48 horas.

Aconsejan (10) la aplicación local de peróxido de zinc. Kelly y Dowell (12) presentan 694 casos tratados con Rayos X y concluyen que se deben utilizar antibióticos.

La histerectomía es aconsejable cuando se sospecha o está presente la lesión en la pared uterina. Sinembargo cuando se logra el diagnóstico las condiciones de la paciente son tan malas que cualquier procedimiento quirúrgico en la mayoría de los casos es fatal. En nuestra serie solamente lo consideramos en un caso pero las malas condiciones de la paciente nos impidieron practicar cualquier tipo de intervención mayor y recurrimos únicamente al curetaje.

La cirugia elimina el órgano lesionado pero Godsick (12) cree que las desventajas son mayores que los resultados obtenidos, ya que expone el peritcneo y demás órganos a la infección y además la paciente gravemente enferma es sometida a los ries- 
gos de la anestesia y de la cirugía. Además sugiere que la cirugía deja más tejidos necróticos sobre los cuales puede crecer el organismo. Por otra parte plantea la situación de que la paciente gravemente enferma que no ha respondido al tratamiento médico posiblemente tampoco sobreviva al quirúrgico.

\section{B - NEUTRALIZAR LAS TOXINAS :}

El tratamiento específico es la administración de la anti-toxina Perfringes. La dosis empleada, según la gravedad del caso es aproximadamente de 250.000 unidades internacionales dadas diariamente, ya sea disuelta en soluciones fisiológicas para la aplicación endovenosa o en inyecciones intramusculares de 50.000 unidades internacionales cada 4 a 6 horas. Estas dosis se continúan por espacio de 4 a 6 días hasta cuando el estado tóxico desaparezca. También la han administrado en forma local intra-uterina (2). En algunos casos presentados por Le French (1) el tratamiento no se comenzó desde las primeras 24 horas y a pesar de esto no parece que se cambió significativamente el pronóstico.

\section{C - ANTIBIOTICOS :}

La penicilina ha sido el antibiótico utilizado en estos casos y su administración debe iniciarse antes de la confirmación del diagnóstico etiológico por el cultivo. Ross (5-12) ha demostrado que es la droga de elección debido a que es efectiva en dosis usuales y que la paciente puede tolerar sin efectos tóxicos altas concentraciones sanguíneas. Por lo tanto también es útil en el período de oliguria de la insuficiencia renal aguda donde se acumula por falla de excreción urinaria. Jones citado por French (1) confirma la efectividad de la Penicilina y recomienda 2.000.000 de unidades diariamente.

Además se han utilizado con buen éxito para prevenir y curar la gangrena gaseosa la Aureomicina, Cloramfenicol, Bacitracina y las sulfas. Parece que la Estreptomicina no tiene efecto benéfico. (12).

\section{D - MEDIDAS DE MANTENIMIENTO:}

Estas medidas consisten en mantener un buen balance de líquidos y elestrolitos, así como también en la aplicación de solu- 
ciones alcaliras y tratando convenientemente la insuficiencia renal aguda en caso de que se presente.

Deben reponerse diariamente la cantidad de líquidos perdidos mediante la administración endovenosa de soluciones de cloruro de sodio y previos balances electrolíticos. Solamente damos líquidos orales en aquellos casos que no presenten vómito. Las transfusiones sanguíneas se practican siempre y cuando la paciente no esté en insuficiencia renal aguda en período de anüria. En la serie de Mahn fue necesario aplicarla en $32 \%$ de los casos.

Aconsejan la aplicación de soluciones alcalinas (bicarbonato de sodio) con el fin de disminuír la cristalización de la hemoglobina liberada por destrucción de los glóbulos rojos (4).

Además de las medidas anteriores se utilizan estimulantes cardiovasculares, dietas altas en proteínas y vitaminas $\mathrm{B}, \mathrm{C}$ y $\mathrm{K}$.

En cuanto a la insuficiencia renal aguda la hemos tratado de acuerdo a las normas publicadas en artículos anteriores (6), teniendo en cuenta cada uno de los períodos clínicos y cuidando los balances electrolíticos y la sobrehidratación del paciente. En ningún caso somos partidarios de la decapsulación (2), de las soluciones de novocaína (2), de forzar líquidos (1-4) y demás medidas para producir diuresis.

\section{SUMARIO}

Presentamos cinco casos de infecciones por Clostridium Welchii, de los cuales cuatro fueron fatales. Resumimos la patología de estas infecciones, hacemos una descripción del cuadro clínico y fijamos las normas para el tratamiento.

\section{BIBLIOGRAFIA}

1-FRENCH A. T.: Postabortal sepsis due to clostridium Welchii simulating traumatic perforation of the uterus. A. M. J. Obst. \& Gynec. 73: 1904, 1957.

2-MAHN B. H., DANTUONO L. M.: Postabortal septicotoxemia due to clostridium Welchii. A. M. J. Obst. \& Gynec. 70: 604, 1955.

3-GEAR E. J., PAXSON N. F., PENMAN R. W.: Another case of post abortal clostridium perfringens infection. Am. J. Obst. \& Gynec. $72652,: 1956$. 
4-DOUglas G. W., CARNEY B. H., PELILlO D.: Postabortal sepsis due to clostridium Weichii. S. Surg., Gynec. \& Obst. 97: 940. 1953.

5-ROSS, R. W. N. L. Inhibition of various clostridia by penicillin in human serum. J. Path. \& Bact. 58: 441, 1946.

6-MUÑZ, S., MORA R.: Insuficiencia renal aguda o Necrosis tubular aguda en Obstetricia. Revista Colombiana de Obstetricia y Ginecología. 9: 485, 1958.

7-WILSON G. S., MILES A. A.: Topley and Wilson's Principles of bacteriology and inmunity. The Williams \& Wilkins Co. Baltimore 1957 (V. 1: 977, 1.015).

8-HADLEY G. G., EKROTH R. D.: Spherocytosis as a manifestation of postabortal clostridium welchii infections. Am. J. of Obst. and Gynec. 67: 691, 1954.

9-BYSSHE, S. M.: The significance of clostridium welchii in the genital tract of pregnant and puerperal women. Am. J. Obst. \& Gynec. 35: $995,1938$.

10-TELFORD GOVAN A. D. An account of the pathology of some cases of Clostridium Welchii infections. J. Path. and Bact. 58: 423, 1956.

11-ISHMAN R. L. y FINCH S C. Postabortal clostridium welchii sepsis with massive hemolysis. The new England Journal of Medicine. 254: 317, 1956.

12-GODSICK W. H., HERMANN H. L. y JONAS G. Uterine gas gangrene: Review with recent advances in therapy and report of three cases. Obs: and Gynec. 3:408, 1954.

13-SMITH ก. T. y CONANT N. F. Zinsser Bacteriology - Eleventh edition Aprıeton Century Crofts, Inc., New York. Pág. 481, 1957.

14-RAMSAY A. M. The significance of clostridium welchii in the cervical swab and Bloodstream in postpartum and postabortum sepsis.

J. Obst. Gyn. Brit. Empire. 48:201, 1936.

15-HILL A. M. Postabortal and Puerperal Gas Gangrene. J. Obst. Gynec. Brit Empire. 43:201, 1936.

16-FALLS F. H. Endometritis and Physometra due to Welch bacilus. Am. J. Obst. Gynec. 25:288, 1933.

17-LASH A. F. Puerperal sepsis. B. Welchii, fatal types. Am. J. Obst. Gynec. 25: 288, 1933.

18-AIKAT B. K. DIBLE H.: The pathology of Clostridium welchii infection. J. Path. and Bact. 71: 461, 1956.

19_WLLI IS A. T. HOBBS G., Some new media for the isolation and identification of clostridia. J. Path. and Bact. 77: 511, 1959. 